\title{
ANTHROPOMETRIC ASSESSMENT AND LIPID METABOLISM BIOMARKERS OF PARENTS OF PEDIATRIC PATIENTS WITH CHRONIC RHEUMATIC DISEASES
}

Lucila Pereira ${ }^{1}$, Ágatha Nogueira Previdelli ${ }^{2}$, Rosana Gomes de Torres Ross ${ }^{3}$, Wellington Douglas Rodrigues ${ }^{1}$, Nicole Carvalho Xavier Micheloni da Silva ${ }^{1}$, Mateus Sabaini Venazzi ${ }^{1}$, Fernando Luiz Affonso Fonseca ${ }^{1}$, Claudio Arnaldo Len ${ }^{1}$, Roseli Oselka Saccardo Sarni ${ }^{1}$, Maria Teresa Terreri ${ }^{1,}$

1. Universidade Federal de São Paulo, São Paulo (SP), Brasil. 2. Universidade de São Paulo, São Paulo (SP), Brasil. 3. Faculdade de Medicina do ABC, Santo André (SP), Brasil.

*Corresponding author: teterreri@terra.com.br

\section{BACKGROUND}

Chronic rheumatic diseases in children and adolescents increase cardiovascular risk. Thus, knowing biomarkers of lipid metabolism and the lifestyle of patients and their parents will allow the development of prevention strategies. The aim of this work is to describe the body mass index, physical activity and lipid metabolism biomarkers of parents of children and adolescents with chronic rheumatic diseases and compare them with those of their children.

\section{MATERIALS AND METHODS}

Cross-sectional study with 91 parents and their respective children diagnosed with juvenile idiopathic arthritis ( $\mathrm{n}=30$ / $33.0 \%$ ), juvenile systemic lupus erythematosus $(n=41 / 45.0 \%)$ and juvenile dermatomyositis $(n=20 / 22.0 \%)$. Anthropometric data, physical activity, total cholesterol (TC) and fractions (LDL-C and HDL-C), non-HDL cholesterol (non-HDL-C) and triglycerides (TG) were evaluated.

\section{RESULTS}

Most parents were female, as were their children ( 89.8 and $83.5 \%$ respectively). The average age of parents was 40.5 \pm 7.4 years. The disease length was $4.5 \pm 3.4$ years and active disease was observed in $56 \%$ of patients. Eighty percent of overweight children/adolescents also had parents with the same nutritional diagnosis; $87.9 \%$ of the parents had waist-toheight ratio $>0.5$. No statistically significant associations were observed when analyzing parents' physical activity compared to their children (Cramer's $V$ test $=0.089, p=0.694$ ). However, $56 \%$ of less active children/adolescents also had parents with a similar classification for physical activity. The prevalence of dyslipidemia of children/adolescents and parents was 83.5 and $82.4 \%$, respectively. Parents and children/adolescents mostly had low HDL-c (52.8 and $64.8 \%$ respectively). There was no association between the frequency of dyslipidemia in general and for TC, LDL-C, HDL-C, and non-HDL-c of parents and their children. Concerning TG, $41.5 \%$ of parents with high TG had children with the same classification, with a weak association (Cramer's V test $=0.238 ; p=0.024$ ).

Parents' demographic characteristics, lifestyle, nutritional status and biochemical data are shown in Table 1.

Table 2 shows the lifestyle, nutritional status, pubertal staging and biochemical data of children and adolescents with rheumatic diseases. 
Table 1. Demographic characteristics, lifestyle, nutritional status, and biochemical data of the parents.

\begin{tabular}{|c|c|c|c|c|c|}
\hline & & $\begin{array}{c}\text { Total } \\
(n=91)\end{array}$ & $\begin{array}{l}\text { Poly JIA } \\
(n=30)\end{array}$ & $\begin{array}{c}\text { JSLE } \\
(n=41)\end{array}$ & $\begin{array}{c}\text { JDM } \\
(n=20)\end{array}$ \\
\hline & & $\mathrm{n}(\%)$ & $\mathrm{n}(\%)$ & $\mathrm{n}(\%)$ & $\mathrm{n}(\%)$ \\
\hline Gender & Female & $76(83.5)$ & $25(83.3)$ & 34 (82.9) & $17(85.0)$ \\
\hline Socioeconomic classification & C & $50(55.0)$ & $17(56.7)$ & $24(58.6)$ & $9(45.0)$ \\
\hline CVD risk in the family & Yes & $12(13.2)$ & $4(13.3)$ & $7(17.1)$ & $1(5.0)$ \\
\hline Physical activity classification & Irregularly active/ sedentary & $52(57.1)$ & $18(60.0)$ & $23(56.1)$ & $11(55.0)$ \\
\hline \multirow{3}{*}{ BMI classification } & Thinness & $1(1.1)$ & $0(0.0)$ & $0(0.0)$ & $1(5.0)$ \\
\hline & Normal & $29(31.9)$ & $10(33.3)$ & $14(34.1)$ & $5(25.0)$ \\
\hline & Overweight & $61(67.0)$ & $20(56.7)$ & $27(65.9)$ & $14(70.0)$ \\
\hline Waist/height ratio & Altered & $80(87.9)$ & $26(86.7)$ & $37(90.2)$ & $17(85.0)$ \\
\hline Total cholesterol (mg/dL) & High & $23(25.3)$ & $7(23.3)$ & $11(26.8)$ & $5(25.0)$ \\
\hline LDL-c (mg/dL) & High & $23(25.3)$ & $8(26.7)$ & $11(26.8)$ & $4(20.0)$ \\
\hline $\mathrm{HDL}-\mathrm{c}(\mathrm{mg} / \mathrm{dL})$ & Low & $59(64.8)$ & $18(60.0)$ & $29(70.7)$ & $12(60.0)$ \\
\hline Triglycerides (mg/dL) & High & $19(20.88)$ & $6(20.0)$ & $9(22.0)$ & $4(20.0)$ \\
\hline Non-HDL-c (mg/dL) & High & $46(50.5)$ & $17(56.7)$ & $19(46.3)$ & $10(50.0)$ \\
\hline Dyslipidemia & Yes & $75(82.4)$ & $23(76.7)$ & $35(85.4)$ & $17(85.0)$ \\
\hline
\end{tabular}

Table 2. Nutritional status, lifestyle, pubertal stage, and biochemical data of children and adolescents with rheumatic diseases.

\begin{tabular}{|c|c|c|c|c|c|}
\hline & & $\begin{array}{c}\text { Total } \\
(n=91)\end{array}$ & $\begin{array}{l}\text { Poly JIA } \\
(n=30)\end{array}$ & $\begin{array}{c}\text { JSLE } \\
(n=41)\end{array}$ & $\begin{array}{c}\text { JDM } \\
(n=20)\end{array}$ \\
\hline & & $\mathrm{n}(\%)$ & $\mathrm{n}(\%)$ & $\mathrm{n}(\%)$ & $\mathrm{n}(\%)$ \\
\hline \multirow{3}{*}{ BMI classification } & Thinness & $9(9.9)$ & $4(13.3)$ & $1(2.4)$ & $4(20.0)$ \\
\hline & Normal & $57(62.6)$ & $22(73.4)$ & $23(56.1)$ & $12(60.0)$ \\
\hline & Overweight & $25(27.5)$ & $4(13.3)$ & $17(41.5)$ & $4(20.0)$ \\
\hline Height for age & Below adequate & $4(4.4)$ & $3(10.0)$ & $1(2.4)$ & $0(0.0)$ \\
\hline Physical activity classification & Less active & $84(92.3)$ & $27(90.0)$ & 39 (95.1) & $18(90.0)$ \\
\hline Waist/height ration & Inadequate & $31(34.1)$ & $6(20.0)$ & $20(48.8)$ & $5(25.0)$ \\
\hline \multirow{3}{*}{ Pubertal stage } & Prepubertal & $28(30.8)$ & $15(50.0)$ & $7(17.1)$ & $6(30.0)$ \\
\hline & Pubertal & $12(13.2)$ & $5(16.7)$ & $2(4.9)$ & $5(25.0)$ \\
\hline & Postpubertal & $51(56.0)$ & $10(33.3)$ & $32(78.0)$ & $9(45.0)$ \\
\hline Total cholesterol (mg/dL) & Borderline/high & $30(33.0)$ & $9(30.0)$ & $15(36.6)$ & $6(30.0)$ \\
\hline LDL-c (mg/dL) & Borderline/high & $19(20.9)$ & $4(13.3)$ & $12(2 ., 3)$ & $3(15.0)$ \\
\hline $\mathrm{HDL}-\mathrm{c}(\mathrm{mg} / \mathrm{dL})$ & Borderline/low & $48(52.8)$ & $14(46.6)$ & $20(48.8)$ & $14(70.0)$ \\
\hline Triglycerides (mg/dL) & Borderline/high & $46(50.6)$ & $12(40.0)$ & $23(56.1)$ & $11(55.0)$ \\
\hline Non-HDL-c (mg/ dL) & Borderline/high & $30(32.7)$ & $8(26.7)$ & $15(36.6)$ & $7(35.0)$ \\
\hline Dyslipidemia & Yes & $76(83.5)$ & $21(70.0)$ & $36(87.8)$ & $19(95.0)$ \\
\hline
\end{tabular}

\section{CONCLUSION}

The present study emphasizes the high prevalence of overweight, dyslipidemia, physical inactivity and central adiposity in the parents of children and adolescents with chronic rheumatic diseases. There was a weak association between TG by parents and their children; but the same was not observed for BMI classification, other fractions of the lipid profile and for physical activity. The findings point to the importance of parental involvement in nutritional intervention strategies.

\section{ACKNOWLEDGEMENTS}

To the Coordenação de Aperfeiçoamento de Pessoal de Nível Superior (CAPES) for granting a scholarship. 


\section{FUNDING}

This study was financed in part by the Coordenação de Aperfeiçoamento de Pessoal de Nivel Superior - Brasil (CAPES) Finance Code 001, grating a scholarship.

\section{REFERENCES}

1. Petty RE, Laxer RM, Lindsley CB, Wendderbun LR. Textbook of Pediatric Rheumatology. 7. ed. Philadelphia: Saunders; 2016.

2. Petty RE, Southwood TR, Manners P, Baun J, Glass DN, Goldenberg J, et al. International League of Associations for Rheumatology. International League of Associations for Rheumatology classification of juvenile idiopathic arthritis: Second Revision. J Rheumatol. 2004; 31(2):390-2.

3. Hochberg MC. Updating the American College of Rheumatology revised criteria for the classification of systemic lupus erythematosus. Arthritis Rheumatol. 1997; 40(9):1725. https://doi.org/10.1002/art.1780400928

4. Petri M, Orbai A-M, Alarcon GS, Gordon C, Merrill JT, Fortin PR, et al. Derivation and validation of the Systemic Lupus International Collaborating Clinics classification criteria for systemic lupus erythematosus. Arthr Rheum. 2012; 64(8):2677-86. https://doi.org/10.1002/art.34473

5. Bohan A, Peter JB. Polymyositis and dermatomyositis. N Engl J Med 1975; 292:344-7. https://doi.org/10.1056/NEJM197502132920706

6. [WHO] World Health Organization. Physical status: the use and interpretation of anthropometry: Report of a WHO Expert Committee. WHO Technical Report Series. 1995; 854:1-452.

7. Faludi AA, Izar COM, Saraiva JFK, Chacra APM, Bianco HT, Afiune Neto A, et al. Atualização da Diretriz Brasileira de Dislipidemia e Prevenção da Arterosclerose - 2017. Arq Bras Cardiol. 2018; 109(Suppl.1):1-76.

8. Expert Panel on Integrated Guidelines for Cardiovascular Health and Risk Reduction in Children and Adolescents: Summary Report. Pediatrics. 2011; 128(Suppl5):S213-56. https://doi.org/10.1542/peds.2009-2107C

9. Statistical Package for the Social Sciences. Version 22.0.0.0. Chicago: SPSS Inc.; 2015. 